\title{
Research on the Construction Index System of China Guilin Tourism Distribution Center
}

\author{
Liang Feng ${ }^{1}, \mathrm{Hu} \mathrm{You}^{2}$ \\ Guilin Tourism University, Guilin, China ${ }^{1}$ \\ Guilin University of Technology, Guilin, China ${ }^{2}$ \\ lf@gltu.edu.cn
}

\begin{abstract}
Guilin tourism development has now become a new trend of individualization, but the tourism distribution center started late compared to other tourist cities of the same level. How to achieve the successful operation of the Guilin tourism distribution center, improve the Guilin tourism public service system, and enhance the tourism service function has become the focus of the development of Guilin tourism. This study conducted an open questionnaire survey using the Delphi method. The interview found that the development of the Guilin Tourism Collection and Distribution Center had problems such as lagging transportation docking mode, imperfect integrated transportation system, insufficient number of outlets, insufficient propaganda, and low awareness. Through interviews and other forms, it is necessary to scientifically plan the development of the Guilin Tourism and Distribution Center, increase the number of outlets for tourism distribution centers, and increase the degree of publicity to increase the awareness of the centers. The government's support plays a key role in the development of Guilin tourism distribution center.
\end{abstract} index

Keywords-China Guilin; Distribution center; Construction

\section{INTRODUCTION}

With the development of China's economy and the continuous improvement of tourism market, the way people choose to travel is more diversified, fragmented and individualized. In 2015, the growth rate of China's free travel market reached $16.7 \%$, which is 3 times that of the world. The consumption data analysis of self-driving tour alone shows that, in 2015, the per capita consumption of one-day selfdriving tour was RMB 376 per day; over-night self-driving tour was 3.2 days per person, the per capita consumption was RMB 2,059.5, the per capita consumption of self-driving tour was RMB 2857[1]. Therefore, the demand of the tourism market is expanding but the supply is very limited, which has formed a huge "individual tourist" market. In the face of this market, the tourism distribution center emerged as a new mode of tourism operation.

As a tourism service organization to meet the travel demand of individual tourists with tourism distribution and consultation, the tourism distribution center also has the social role of creating tourism economic benefits and propagandizing city image [2]. In 1998, the first tourism distribution center of China was set up in Shanghai, and it became a model for all cities in the country to set up tourism distribution centers.
Since then, Beijing, Hangzhou and other cities, on the basis of the experience of Shanghai tourism distribution center, have set up tourism distribution centers in combination with their own urban characteristics.

Guilin is a famous international tourist attraction in the world. It has rich tourist resources; especially the effect of the Spring Festival Gala in 2017, the number of visitors and total tourism consumption in Guilin has set a new high. Only in the first half of 2017 , the city received $40,058,900$ tourists, the total tourism consumption was RMB 46.225 billion, and the per capita consumption was RMB 1,153[3]. The early consulting service center of Guilin is based on simple consulting services such as consultation and network service. The medium-term business extends to telephone consultation and creating websites that can provide a series of travel consultation such as food, housing, travel, sightseeing, shopping and entertainment. The present intelligent tourism is carrying out the construction of consulting sites and network service points on the basis of the original public service system, and is developing towards tourism distribution center. Nowadays, the proportion of individuals, families and selfdriving visitors to Guilin is increasing greatly. Guilin's tourism mode is also changing from "sightseeing type" to "leisure vacation type"[4]. The construction and improvement of the tourism distribution center system is an important measure to meet the needs of the development of individual tourist and free travel market under the present individual tourist development trend.

This paper takes Guilin, the famous international tourism city, as the object of study, and uses Delphi method to carry out an open questionnaire survey. Through interviews and questionnaire survey, it finds out the problems in the development of Guilin tourism distribution center, and puts forward the solutions and suggestions for these problems, and also provides a reference sample for the development of tourism distribution centers in small and medium tourism cities. 


\section{DeVELOPMENT STATUS OF GUILIN TOURISM DISTRIBUTION CENTER}

In 2000, the form of tourists in Guilin gradually developed towards dispersion. Since 2016, the dispersion trend is more obvious, and the proportion of individual tourists and teams even reaches 8:2. In order to meet the needs of the development of the dispersion trend, it is necessary to improve the function of the public management service system. In 2002 , the relevant departments of Guilin set up the Municipal Consulting Service Center (changed into Municipal Public Service Management Office later). In August 2012, Guilin in order to further optimize and promote the self-driving tourism environment, promote the transformation and upgrading of tourism, under the guidance of the Municipal Tourism Bureau and the Municipal Tourism Public Service Management Office, the Guilin Tourism Self-driving Service Area Construction Plan was formally implemented; at the end of 2014, Guilin West Station was officially opened and put into use to undertake a large number of tourists to Guangxi via passenger-dedicated railways of Guizhou-Guangxi Railway and Hunan-Guangxi Railway; In 2017, Guilin North Comprehensive Passenger Hub and Yangshuo Bus Station project were included in the "Thirteenth Five-Year" comprehensive passenger hub planning of the Ministry of Transport. After the two projects are completed and put into use, it will realize "zero distance transfer" among a variety of transportation tools, create an "unblocked Guilin" transportation system, perfect the seamless travel shuttle service on the ground and resource integration, and promote the international tourist attraction construction and the social and economic development of Guilin.
In April 2016, Guilin Tourism Distribution Center was officially opened in Qintan Bus Station. The establishment of the distribution center provides a "tourist butler" for tourists, and it is an important step for Guilin to create "intelligent" tourism public service.

Guilin Tourism Distribution Center O2O (Online To Offline) platform is a joint investment of Guilin Tourism Development (Group) Corporation and Jintianxia Investment Management Co., Ltd. It adopts the business model of "government leading, enterprise management, market operation". The distribution center mainly arranges and takes care of the travelers' schedule through perfecting the seamless travel shuttle service on the ground and resource integration. At present, there are seven tourist service consulting sites in the urban area of Guilin.

The main functions of Guilin Tourism Distribution Center include Guilin tourism image display, tourist distribution (including airport, high speed rail transit station transfer), tourism consulting service, tourism product customization service, tourism route design service, tour guide service, personalized custom service, tourism right protection service, locomotive ticket agency service, scenic area (spot) ticket and accommodation agency service, city terminal function, local products display, logistics and automobile lease service, etc. At the same time, it signs contracts and cooperates with Guilin Airlines and carries out Guilin air tour service. All these tourism services are managed by Guilin Tiandi Holiday Travel Co., Ltd. established by Guilin Tourism Corporation Limited [5].

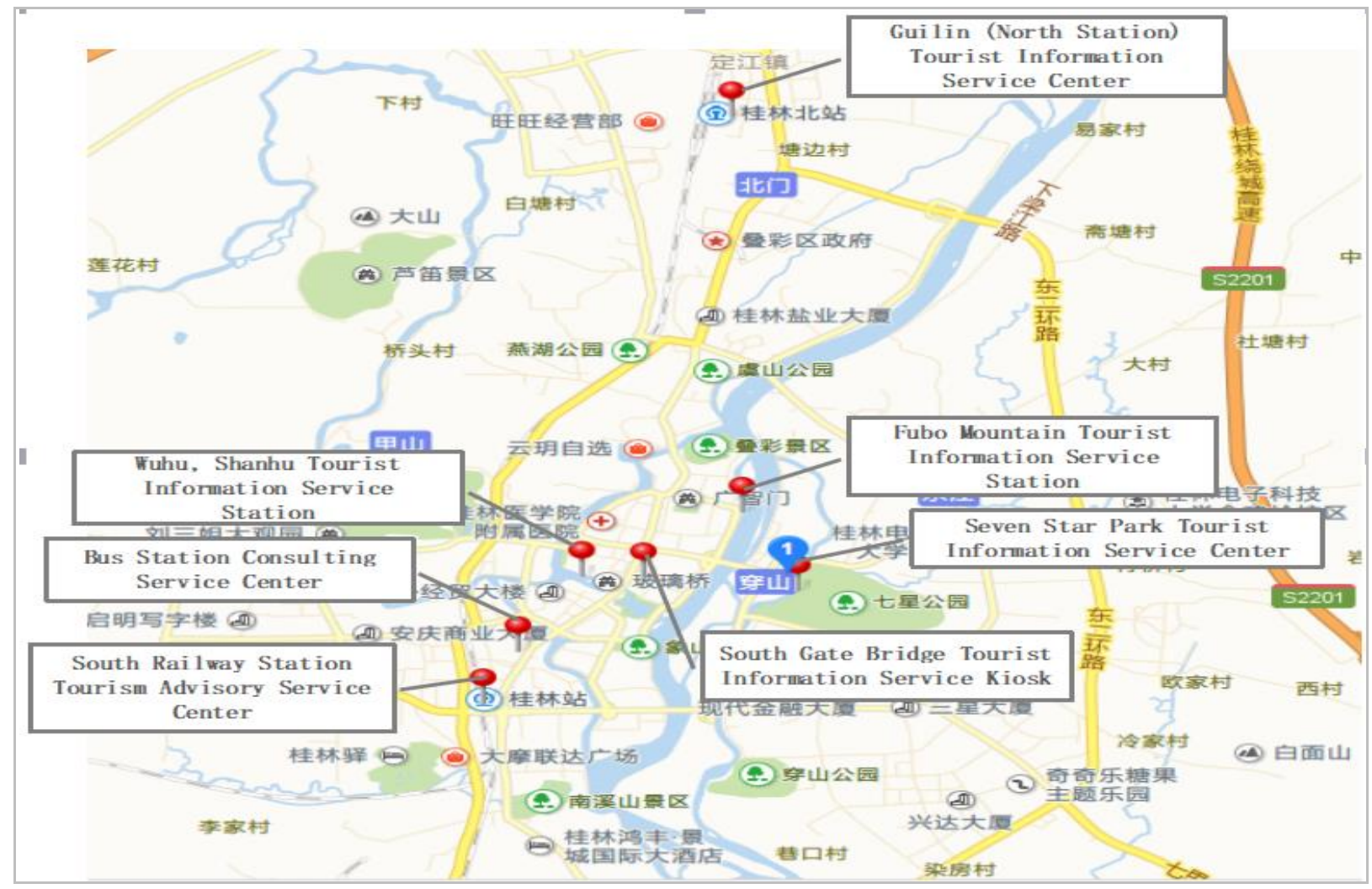

Fig. 1. Distribution map of tourism consulting service stations guided by district governments of Guilin in 2017 


\section{DELPHI METHOD}

Through open questionnaire, 3 project leaders of Tourism Development Committee in the tourism administration department of Guilin, 3 tourism industry practitioners (tourism association, scenic spot, tourist journalist) and 2 tourism research experts were interviewed from June 15, 2017 to July 13, 2017. According to the basic principle of demography, male accounts for $20.8 \%$ of the total number and female accounts for $12.5 \%$ of the total number; those with working years of 3-7 years account for $8.3 \%$ of the total number, those with working years of $8-12$ years account for $8.3 \%$ of the total number, and those with working years over 13 years account for $16.8 \%$ of the total number; administrative personnel account for $20.8 \%$ of the total number and experts and scholars account for $12.5 \%$ of the total number.

\section{A. Questionnaire composition}

Before the first open questionnaire survey, this paper collated three major directional questions in view of the development status of Guilin Tourism Distribution Center and combined with a large number of literature references. They are also the contents of the open questionnaire survey. The details are as follows:

Q-1: What factors should be taken into account in the construction of Guilin Tourism Distribution Center under the trend of individual tour?

Q-2: What are the limiting factors in the process of construction of Guilin Tourism Distribution Center?

Q-3: What technical support does the government provide in the process of construction of the distribution center?

\section{PROBLEMS EXISTING IN GUILIN TOURISM DisTRIBUTION CENTER}

\section{A. The traffic docking mode is lagging behind, and the comprehensive transportation system is weak.}

Guilin Bus Station is the main transport hub to reach the destination scenic spot after connecting Guilin's large traffic. After arriving at Liangjiang Airport or Guilin North Station and West Station by plane or high speed rail, the tourists must first take the shuttle bus or bus to Guilin Bus Station and then transfer to the minibus to the scenic spot, which increases the transfer time virtually. And the public transport service system in the urban area of Guilin mainly focuses on public service, and is short of tourism buses from the main passenger points directly to the scenic spots. The traffic connection service seriously affects the tourists' enthusiasm.

\section{B. The number of tourist service outlets is insufficient}

There are seven tourism consulting points established under the guidance of the government in the urban area of Guilin. Compared to other tourism cities at the same level, the number of outlets is small. From Figure 1, it is known that the existing tourism consulting points are relatively concentrated, and outlets are set up only in some traffic stations, people gathering places and scenic spots; the main entrances of urban traffic (airport, etc.) and the main tourism channels (Guiyang Highway, etc.) are ignored. And according to the author's investigation, it is found that the consulting centers established by the Guilin government in various important stations has not played their actual tourist reception function under the influence of various factors, resulting in the waste of resources.

\section{The tourism distribution center has weak publicity and low awareness}

Since the establishment of Guilin Tourism Distribution Center, the official website of Guilin Tourism Distribution Center cannot yet be searched on Baidu Engine and other Internet platforms. The information about the distribution center is very little and chaotic, and it lacks official introduction of the distribution center, which has seriously affected the awareness of Guilin Tourism Distribution Center in tourists and citizens. During the field investigation, it was found that the local citizens' awareness of Guilin Tourism Distribution Center was very low. Many citizens knew the tourism distribution center but did not understand, and many citizens even didn't know the tourism distribution center. Foreign individual tourists and local residents are the main service objects of the tourism distribution center. At present, the low awareness of Guilin Tourism Distribution Center directly affects the travel choice of local citizens and foreign tourists.

\section{SOLUTIONS}

\section{A. Planning the transportation system scientifically}

Guilin should re-plan the existing transportation system scientifically and break the mechanized design of fixed lines and fixed stations to cater for market demand and achieve humanized design. In detail, add direct shuttle buses to the main tourist areas (scenic spots) at the main traffic hubs, such as High Speed Rail North Station and West Station or Liangjiang Airport. Plan routes according to the preference of the passenger sources of high speed rail lines (for example, the passengers from Guangdong area prefer Yangshuo, shuttle buses from the airport direct to Yangshuo can be added). Add large hotels and scenic spot stops on the existing bus routes; note the name of large hotels and scenic spots on the existing route sites, and add the name of large hotels and tourist hubs of scenic spots. Set up special tourist lines and direct buses at the scenic spots in the urban area to form a closed tour of important scenic spots, such as the special line tour of scenic spots in the urban area of Elephant Trunk Hill, Folded Colours Hill, Fubo Hill and Seven Star Park; set up special tourist lines from primary traffic hubs direct to important scenic spots, such as special line tour from the airport direct to the Elephant 
Trunk Hill scenic area; and open special line sightseeing buses, such as special line tour of "two rivers and four lakes".

\section{B. Setting up tourism distribution center outlets}

Set up large tourism distribution centers at all primary traffic stations (airports, trains, buses), large people gathering places (Central Plaza, Jiatianxia Plaza) and the main traffic entrances of the city, and set up small tourism distribution centers on the main tourism channels (Guiyang Highway, east bank green road, Guilin to Longsheng, Xingan, Ziyuan and other main destinations. The distribution centers are vertically managed by the headquarters, and customers in all distribution centers can enjoy standardized products and service guarantees. The ownership of the name of "Guilin Tourism Distribution Center" belongs to the government, and the right of use belongs to the "Distribution Center Company".

\section{Enhancing propaganda to improve the awareness of the distribution center}

Establish the official website of "Guilin Tourism Distribution Center" according to the actual situation of Guilin and under the guidance of the government, answer the questions put forward by the netizens online, and systematically propagandize other tourism consulting points of Guilin; advertise on television, radio and other media channels, and distribute publicity handbooks the citizens of Guilin, to enhance the citizens' recognition, form joint effect, and make citizens consciously promote propaganda.

Standardize and reorganize the existing tourism distribution centers and adhere to standardized management in actual operation. Win the trust and praise of tourists with high quality services, and let tourists publicize to expand the awareness of the distribution center [6].

Distribute newspapers and magazines and broadcast on means of transportation to Guangxi, set up large signboards on main traffic roads, and release information of the tourism distribution center at the accommodation, catering and shopping sites in Guilin.

\section{CONCLUSION}

The construction and improvement of Guilin tourism distribution center system is an urgent problem to be solved in the current tourism development of Guilin, and the effective support from the government is crucial. Guilin can rely on Liangjiang International Airport, Guilin High Speed Rail Station (North Station, West Station) and Guilin Station to build large tourism distribution centers and provide international tourism service; set up small tourism distribution centers on main tourism channels (Guiyang high speed intersection) to provide localized and personalized service. From the entrance of Guilin to the urban area and the county, primary distribution centers, secondary distribution centers and tertiary distribution centers can be set up to form a complete and seamless service system, characterized by onestop service of intelligence, convenience and comprehensive functions, to promote Guilin tourism international service brand.

\section{ACKNOWLEDGMENT}

This paper is one of the Guilin Tourism University Scientific research fund Project (2016ZD06). Also is one of the phased achievements for the research subject: Research on Integrative Development of Guangxi leisure Sports Industry and Tourism Industry (17FTY004). And one of research results funded by Guilin Tourism University key discipline tourism management Research funding project.

Author: Liang Feng (1983- ), male, born in Zibo in Shandong Province, doctor of sports, lecturer, research area: leisure sports tourism industry.

\section{REFERENCES}

[1] China's Independent tourism market drives global tourism consumption [EB/OL].http: //news.hexun.com/2016-01-19/181897944.html

[2] Y. Q. Wang. Research on Enhancing Functions of Urban Tourist Centers_-Case Study of Shanghai[D].Thesis for master Degree in East China Normal University, 2009

[3] Y. Y. Chen. Guilin is a hot Tourist destination in the first half of the year [N]. Guilin Evening News, 2017-7-14 (05)

[4] Guilin Tourism Distribution Center unveiled operation.[EB/OL].https://www.anxin.com/wiki/360daidai_565102.html

[5] Y. B. Li. Guilin Tourism Distribution Center O2O Platform [N].Guilin Daily, 2016-4-13 (01).

[6] M. M. Tian. Research on System Establishment and Improvement of Zibo Tourism Distribution Center[D].Thesis for master Degree in Shandong Normal University, 2013

[7] Q. Liu. Research on Construction and Perfection of ASEAN-oriented Immigration Tourism Distribution Hub System in Guangxi [J].Journal of Nanning Polytechnic, 2016, 21(01):40-42. 